\title{
Short-Term and Long-Term Effects of Incidental Vocabulary Acquisition and Instructed Vocabulary Teaching
}

\author{
Mehdi Ghobadi (Corresponding author) \\ Institute for Humanities and Cultural Studies (IHCS), Tehran, Iran \\ E-mail: mehdi.ghobadi64@gmail.com \\ Mostafa Shahriar \\ Payame Noor University-Tehran Branch, Tehran, Iran \\ E-mail: Shahriar333@yahoo.com \\ Arash Azizi \\ Islamic Azad University Central Tehran Branch, Tehran, Iran \\ E-mail: Aziziaurash@gmail.com
}

\author{
Received: 04-03-2016 \\ Accepted: 13-05-2016 \\ Advance Access Published: May 2016 \\ Published: 01-07-2016 \\ doi:10.7575/aiac.ijalel.v.5n.4p.212 URL: http://dx.doi.org/10.7575/aiac.ijalel.v.5n.4p.212
}

\begin{abstract}
The present empirical study was conducted to compare instructed vocabulary teaching and incidental vocabulary acquisition that are two common approaches to teaching second language (L2) vocabulary in the literature. For this purpose, 53 Iran learners of English as a Foreign Language were selected from a larger sample and were then randomly assigned into a control group and two experimental groups as the participants of the study. The participants in the groups received placebo instruction while those in the experimental groups were either explicitly instructed or incidentally exposed to a number of targeted words (TWs) selected for the purposes of the study. The results of an immediate posttest of the TWs demonstrated that the participants in both experimental groups benefited from instruction on/exposure to the TWs compared to the participants in the control group who were neither instructed on nor exposed to the TWs. The results of a delayed posttest indicated that, though there was a difference between the two experimental groups in the immediate posttest with respect to the acquisition of the TWs, the difference faded away in five-week interval as the experimental groups performed rather similarly on the delayed posttest. At the end, the implication of these findings for L2 vocabulary research and pedagogy would be discussed, along with some suggestions for researchers who wish to follow this trend of research.
\end{abstract}

Keywords: Intentional Vocabulary Teaching, Incidental Vocabulary Acquisition, Short-Term Effects, Long-Term Effects, Target Words

\section{Introduction}

Although researchers have different views of what element (e.g., pronunciation, grammar, and vocabulary) is the most important component in teaching and learning a second language (L2), they do agree that vocabulary knowledge is at the top of the list. In fact, some researchers contend that L2 communication become somehow impossible unless the language learner, or the nonnative speaker, has a good command of L2 words (e.g., Coady \& Huckin, 1997; Gu, 2013; Lewis, 1993, 1997). In the same manner, the followers of some language teaching methods and approaches have paid the most attention to the teaching of L2 words and related associations (e.g., collocations, idioms, pre-fabricated phrases). The most famous of these methods and approaches is the Lexical Approach founded by Lewis (1993, 1997) who stressed language teachers that lexicon (i.e., vocabulary knowledge) is where they should focus most of the classroom time on. Consequently, researchers and teachers have begun attempts to investigate the ways L2 vocabulary knowledge could be taught best to language learners.

The fact, however, is that the state of affairs has not changed so much since the introduction of the lexical approach. Although some improvements have been made in recent decades (see Bogaards \& Laufer, 2004; Takač, 2008), teachers are still confused about what is the best way to teach L2 vocabulary items. The most discussed issue is whether it is necessary to teach new L2 words intentionally to learners or, otherwise, learners have the required cognitive mechanism to learn new L2 words from processing whatever L2 input they receive from the surrounding environment (e.g., classroom, audiovisual equipments, and language learning materials) (Takač, 2008). Even though a large number of studies have been carried out on this issue (see Coady \& Huckin, 1997; Laufer \& Girsai, 2008; Schmitt, 2008), the discussion seems to have a long way to be settled. Therefore, the aim of the present investigation is to conduct a comparative study to determine the positive effects of incidental vocabulary acquisition and instructed vocabulary teaching on improving learners' L2 vocabulary knowledge. To set the picture in its right place, the study aimed to 
investigate both the short-term and long-term effects of incidental vocabulary acquisition and instructed vocabulary teaching on improving Iranian intermediate EFL learners' L2 vocabulary knowledge.

\section{Literature Review}

As far as L2 vocabulary instruction is concerned, perhaps the most important question is whether learners should be taught on L2 words intentionally or, otherwise, they should be allowed to acquire L2 words by themselves through processing whatever L2 input they receive from the classroom context (Coady \& Huckin, 1997; Laufer \& Girsai, 2008). The fight over this issue is far from being settled, as the researchers in both groups have been successful in providing theoretical arguments to support their claims on the superiority of one approach to L2 vocabulary teaching/learning over the other. To make the situation even more complicated, these researchers have gathered sufficient evidence to back their own theoretical arguments.

To begin with, the supporters of incidental vocabulary acquisition believe that L2 learners may acquire L2 words more efficiently if they are not intentionally pushed towards learning L2 words. In other words, these researchers contend that L2 words are acquired better if learners learn them incidentally. In incidental vocabulary acquisition, the learner is exposed to L2 input with the hope that they would use their own cognitive mechanisms to solve language comprehension problems they encounter when processing the text. The theoretical argument posed for incidental vocabulary acquisition is that this type of L2 vocabulary acquisition engages the learner in deeper L2 learning processes that, in return, would result in a longer retention of the acquired L2 words. A wide range of evidence has been gathered in the literature to support these propositions (Huckin \& Coady, 1999; Laufer \& Hulstijn, 2001; Reynolds, 2015; Wode, 1999). For instance, Reynolds (2015) conducted a study that investigated incidental vocabulary acquisition by Mandarin Chinese learners of English as a Foreign Language. For this purpose, Reynolds (2015) asked the participants to read an English novel of 37,611 words of which 49 were the TWs. The participants were required to read the novel within two weeks without any explicit teacher guidance or instruction. The results of the study indicated that the participants could, on average, recall the meanings of 10 of the TWs in a posttest when asked to do so. Furthermore, when the participants' achievements of the TWs were assessed through a meaning-recognition task, they, on average, could recognize the meanings of 25 TWs. These results were interpreted as showing that EFL learners could acquire TWs incidentally when they were exposed to L2 input materials. These findings are supported by the earlier studies of incidental L2 vocabulary acquisition (e.g., Eckerth \& Tavakoli, 2012; Joe, 1998; Laufer \& Hulstijn, 2001; Webb, 2008; Wode, 1999).

On the other hand, the other group of researchers argues that instructed vocabulary teaching makes learners' mental resources free of contextual complexities involved in incidental vocabulary acquisition, leaving more free space in the learner's mind to process the TWs (Schmitt, 2008). This happens because, in most instructed vocabulary teaching techniques (e.g., wordlists, contrastive analysis of the TWs, L2 word memorization), the TWs are often decontextualized for the purpose of focused instruction and acquisition. These supporters also believe that instructed vocabulary teaching helps learners make associations between L2 word forms and their meanings more easily, either directly or through the mediation of learners' L1s (Meara, 2009; Schmitt, 2008; Takač, 2008). Along with these theoretical arguments in favor of instructed vocabulary teaching, the researchers have provided us with empirical evidence (e.g., Laufer \& Girsai, 2008; Walters \& Bozkurt, 2009; Webb, 2005). For example, in Webb's (2005) study, the participants received L1 equivalents for a numbers of TWs and were then asked to use the TWs in sentences. The results of Webb's (2005) study indicated that the students in the experimental group who received L1 equivalents for the TWs and used them in their own L2 sentences learned more of the TWs than those in the control group. Walters and Bozkurt (2009) had their participants record the TWs, and their multiple aspects, in a notebook and later had the TWs incorporated in classroom activities. Their results indicated that this type of vocabulary instruction had positive effects on their participants' L2 vocabulary knowledge. Finally, Laufer and Girsai (2008) examined whether the use of contrastive analysis and L1 translation would increase their participants' acquisition of the TWs. The results of the study showed that the participants who were instructed on the TWs through contrastive analysis and L1 translation were more successful on the posttests of the TWs (i.e., a receptive posttest and a productive posttest) than those participants who were taught through the other approaches, which were less explicit in nature.

Although the issues of incidental vocabulary acquisition and instructed vocabulary teaching have appealed to many scholars in the field of L2 research, the problem is that there are a few studies that have carried out comparative analyses, investigating incidental vocabulary acquisition and instructed vocabulary acquisition simultaneously. This problem is exactly the motivation for doing the present study; i.e., to see whether there are differences between incidental vocabulary acquisition and instructed vocabulary teaching. In addition, a second purpose of the present study is to determine whether potential positive effects of instructed vocabulary teaching and incidental vocabulary acquisition will be retained by L2 learners over time.

\section{Research Questions}

As mentioned above, the present study was set to investigate whether there would be a difference between the effects of instructed vocabulary teaching and incidental vocabulary acquisition on the improvement of Iranian intermediate EFL learners' L2 vocabulary knowledge. The study also aimed to determine whether potential positive effects of these two approached to L2 vocabulary will be retained by learners over time. Therefore, the following research questions were formulated to serve the purposes of the present study: 
Research Question 1: Is there a difference between the effects of instructed vocabulary teaching and incidental vocabulary acquisition on Iranian intermediate EFL learners' L2 vocabulary knowledge in a short term?

Research Question 2: Is there a difference between the effects of instructed vocabulary teaching and incidental vocabulary acquisition on Iranian intermediate EFL learners' L2 vocabulary knowledge in a long term?

\section{Method}

\subsection{Participants}

The participants of the present study were selected from among the intermediate EFL learners enrolled in a private language institute in Tehran, Iran. A total number of 64 learners in the institute were identified as intermediate learners who were found suitable for the purposes of the study. However, to make sure that the participants to be included in the study were homogenous as far as their proficiency of the English language was concerned, the initial 64 learners were asked to take a general English proficiency test designed by the institutes' stakeholders. The results of the test indicated that, of the initial 64 learners, 53 learners could pass the criterion of being an intermediate EFL learner. This criterion allowed us to have participants from a homogenous English language proficiency level in the present study. After taking the general English language proficiency test, the selected participants were randomly assigned to one control group and two experimental groups. The control group consisted of 17 participants and each of the experimental groups consisted of 18 participants. The participants of the study aged from 19 to 32. Further, the participants had the Persian language as the mother tongue.

\subsection{Target words}

24 English words were selected as the targeted words (TWs) in the present study. The TWs were sampled through the following procedure. First, a series of 42 English words were sampled from the English vocabulary textbooks available in the market. The words were sampled because they were thought to be supposedly unknown to intermediate EFL learners as judged by two English language teachers in the present study. However, to make sure that the sampled words were unknown to such learners, a pilot study was conducted with an independent sample of 10 EFL learners who were at the same English proficiency level as the participants taking part in the present study. The participants in this pilot study were presented with the sampled words and were asked to do two things. First, they were asked to show, by checking YES/No, whether they had encountered each of the sampled words before. If the participant checked one of the sampled words as YES, he/she was then required either to write the meaning of the words (in English or Persian) or to compose an English sentence with the word embedded in it. Then the pilot participants' answers were scrutinized to finalize the list of the TWs for the present study. From the sampled words, only those words were included in the final list of the TWs that were checked by all the pilot participants as NO. If a word was checked by even one of the pilot participants as YES and was then defined, or used in an English sentence, by the participant, the word was excluded from the final list of the TWs. The pilot study left us with 24 English TWs that were used as the focus of the present study.

\subsection{Procedure}

The procedure of the study took four sessions to complete, each sessions lasting about 20 minutes. The treatment was held in two days in a row. Each treatment day included a morning session and an afternoon session. The reason for such compact sessions was that we did not want to let time intervals between the sessions affect the results of the study. As one of the purposes of the present study was to compare the effects of two different approaches to improving L2 vocabulary knowledge (i.e., instructed vocabulary teaching and incidental vocabulary acquisition) on the immediate acquisition of a set of TWs, any long-term interval between the treatment sessions would distort any conclusions regarding such effects.

The participants in the present study received particular interventions according to the group to which they were assigned. The participants in the control group did not receive any instruction on the TWs. Rather, to observe research ethics (Oliver, 2003), the participants in this group were asked to read an English novel during the time the data collection procedure was being carried out with the three groups. The novel the participants in the control group read during this time period was Jack London's White Fang. To make sure that the participants would not be exposed to the TWs through the novel, a computer analysis of the novel against the TWs was conducted. The analysis showed that none of the TWs was used in the novel. The participants in the control group read the novel White Fang for four sessions, each session consisting of 20 minutes.

The participants in the second group, i.e., the Incidental Vocabulary Acquisition (IVA) group, were exposed to the TWs through reading comprehension texts. Four texts were prepared for this purpose, which were extracted from the available English reading comprehension textbooks in the market. The selected reading comprehension texts were modified so that the TWs could be inserted into them for the purposes of the study. Each selected text contained six of the TWs. In each treatment session, the IVA participants were allowed to read one of the selected texts as many times as he/she wished within a limited time of 20 minutes. However, the IVA participants were told that they are not allowed to look words up in dictionaries or to consult with their classmates about the meanings of words and sentences.

Finally, the participants in the third group, i.e., the Instructed Vocabulary Teaching (IVT) group, were taught on the TWs explicitly by the teacher. To keep the Time-on-Task constant for all the three groups, the teaching of the TWs to the IVT group in each of the four treatment sessions (i.e., six TWs per session) lasted 20 minutes. During this time period, the teacher wrote the six TWs for the session on the whiteboard along with their definitions in the participants' 
mother tongue (i.e., Persian). Whenever possible, the teacher presented the IVT participants with a contrastive analysis of the TWs and their Persian equivalents. The teacher, then, wrote down example sentences on the whiteboard in which each of the TWs for the session were inserted. As a final activity, the learners were told they could ask any questions regarding the definitions and contextualized uses of the TWs for the session.

Right after the treatment sessions, an immediate posttest of the TWs was administered to the participants in all the three groups to assess the participants' acquisition of the TWs. The test was of a multiple-choice format in which the participants were required to choose from among the four English words given one word (i.e., the TW) that completed the meaning of a stem sentence. Five weeks after the treatment sessions and the immediate posttest, a delayed posttest of the TWs was administered to the participants in all the three groups to assess the participants' retention of the acquired TWs. The delayed posttest was similar in format to the immediate posttest of the TWs with stem sentences and the distracters being different from those in the immediate posttest. In both posttest sessions, the participants were allowed 30 minutes to complete the test. In addition, the total score on each posttest was 24 and no guessing-correction was applied to the participants' scores on the posttests.

\section{Results}

Table 1 presents the descriptive statistics for the participants' performance on the immediate posttest of the TWs. The participants in the IVT group obtained the highest mean score on the immediate posttest, with the participants in the IVA group obtaining the second highest mean score on the immediate posttest. The participants in the IVT group had a mean score of 19.62 and a standard deviation of 4.42 whereas the participants in the IVA group had a mean score of 11.35 and a standard deviation of 3.20 in the immediate posttest of the TWS. The participants in the control group obtained the lowest mean score on the immediate posttest. They had a mean score of 4.38 and a standard deviation of 1.32 in the immediate posttest of the TWs.

Table 1. Descriptive Statistics of the Immediate Posttest

\begin{tabular}{cccc}
\hline Group & $\mathrm{N}$ & $\mathrm{Mean}$ & Std. Deviation \\
\hline Control & 17 & 4.38 & 1.32 \\
Incidental Vocabulary Acquisition & 18 & 11.35 & 3.20 \\
Instructed Vocabulary Teaching & 18 & 19.62 & 4.42 \\
\hline
\end{tabular}

Table 2 presents the descriptive statistics for the participants' performance on the delayed posttest of the TWs. The participants in the IVT group obtained the highest mean score on the immediate posttest, with the participants in the IVA group obtaining the second highest mean score on the immediate posttest. The participants in the IVT group had a mean score of 14.12 and a standard deviation of 2.95 whereas the participants in the IVA group had a mean score of 12.84 and a standard deviation of 2.66 in the immediate posttest of the TWS. The participants in the control group obtained the lowest mean score on the immediate posttest. These participants had a mean score of 3.26 and a standard deviation of 1.09 in the immediate posttest of the TWs.

Table 2. Descriptive Statistics of the Delayed Posttest

\begin{tabular}{cccc}
\hline Group & $\mathrm{N}$ & $\mathrm{Mean}$ & Std. Deviation \\
\hline Control & 17 & 3.26 & 1.09 \\
Incidental Vocabulary Acquisition & 18 & 12.84 & 2.66 \\
Instructed Vocabulary Teaching & 18 & 14.12 & 2.95 \\
\hline
\end{tabular}

The descriptive statistics presented above showed that there were differences between the three groups in the present study; however, differences in raw mean scores do not tell us anything about whether they have any meaning in statistical terms. Therefore, the data collected from the participants were submitted to the software of SPSS, Version 19, for the purpose of inferential analysis. The inferential test used in the present study for this purpose was one-way between-subject analysis of variance (AVOVA). One-way between-subject AVOVA is used to test whether there is a difference between three or more groups by comparing their mean score differences (Pallant, 2001).

Research Question 1 of the present aimed to determine whether there would be a difference in the effects of three instructional procedures (i.e., instructed vocabulary teaching, incidental vocabulary acquisition, and placebo instruction) on the participants' immediate acquisition of the TWs. The participants' scores on the immediate posttest of the TWs were submitted to one-way between-group AVOVA to find the answer to this question. The results of AVOVA for Research Question 1 have been displayed in Table 3. There existed a statistically significant difference at the $p<.05$ level among the three groups' mean scores on the immediate posttest of the TWs: $F(2,51)=7.14, p=.000$. 
Table 3. ANOVA Results for the Participants' Performance on the Immediate Posttest

\begin{tabular}{cccccc}
\hline & Df & Mean Square & F & Sig. \\
\hline Between groups & 2 & 26.448 & 7.14 & .000 & \\
\hline
\end{tabular}

From Table 3, it can be concluded that there is at least one difference between the three groups of participants as far as their performance on the immediate posttest of the TWs is concerned. However, ANOVA does not tell us where the potential difference(s) between the groups lies. For this purpose, it is important to conduct post-hoc comparisons between the groups. Tukey Honestly Significant Difference (HSD) test is the statistical test used for this purpose (Pallant, 2001). Post-hoc comparisons using the Tukey HSD test indicated that the mean scores for the IVA and IVT groups significantly differed from the mean score for the control group in the immediate posttest of the TWs. In addition, there was a statistically significant difference between the mean score for the IVT group and the mean score for the IVA group in the immediate posttest of the TWs.

The results of one-way between-subject AVOVA for Research Question 2 have been displayed in Table 4. There existed a statistically significant difference at the $p<.05$ level among the three groups' mean scores on the delayed posttest of the TWs: $F(2,51)=4.23, p=.001$. Post-hoc comparisons using the Tukey HSD test indicated that the mean scores for both experimental groups were statistically different from the mean score for the control group. However, the results indicated that there was no statistically significant difference between the mean score for the IVT group and the mean score for the IVA group in the delayed posttest.

Table 4. ANOVA Results for the Participants' Performance on the Delayed Posttest

\begin{tabular}{cccccc}
\hline & Df & Mean Square & F & Sig. \\
\hline Between groups & 2 & 18.209 & 4.23 & .001 & \\
\hline
\end{tabular}

\section{Discussion}

The results of the present study indicated that both incidental vocabulary acquisition and instructed vocabulary teaching are effective for the development of intermediate EFL learners' L2 vocabulary knowledge. The findings were to be expected as there is a wealth source of evidence in the literature showing that L2 learners can benefit from both explicit and implicit approaches to teaching L2 words. The findings can be interpreted if we resort to SLA approaches that have taken a cognitive approach to explaining L2 acquisition and use phenomena. According to Schmidt's (1990) noticing hypothesis, mental consciousness/awareness is the least requirement for the acquisition of L2 structures, including L2 words. In fact, Schmidt (1992) himself implies that mental consciousness is not only necessary for the learning process, it is also sufficient for the process. In the present study, the participants in the two experimental groups (i.e., IVA and IVT groups) had the chance to mentally notice the TWs. The mental awareness of the participants in the IVT group was consciously directed towards the TWs, putting the participants in the position to learn the TWs. The participants in the IVA group had also the chance to mentally notice the TWs. Though these latter participants' mental awareness was not directed towards the TWs by an outside source (e.g., teacher, instructional materials, etc.), they nevertheless had to pay attention to, and subsequently process, the TWs as their meanings were essential to the comprehension of the texts the IVA participants were required to read during the treatment sessions.

The superiority of the participants in the IVT group over the participants in the IVA group in the immediate posttest of the TWs can be interpreted using Ausubel's (1968) meaningful learning theory. According to this theory, there is a distinction between rote learning and meaningful learning; rote learning involves the learning of disparate learning items with no associations with previously learned items in the mind while meaningful learning happens when newlylearned materials are attached to previously-acquired materials in the mind. The point is that while the speed of learning is faster in rote learning as this kind of learning does not require the learner to cope with the complexities of the learning context, forgetting happens faster too in this kind of learning, because the learned materials are not associated with other mental structures in the mind (Ausubel, 1968; Dörnyei, 2009). The situation is reverse in meaningful learning. Learning happens slower in meaningful learning and so does forgetting. Therefore, it could be concluded that since the IVT participants in the presented study learned the TWs as separate entities, they succeeded to acquire more of them in a short-term period. The IVA participants, on the other hand, had to face the contextual complexities of the texts they read in the treatment sessions when they were acquiring the TWs incidentally, resulting in them acquiring fewer TWs than the IVT participants do.

The results of the ANOVA for the delayed posttest indicated that the participants in both of the experimental groups were successful in retaining the acquired TWs over the five-week interval from the immediate posttest to the delayed posttest. This finding shows that the L2 vocabulary teaching/acquisition approaches investigated in the present study did not only help the participants acquire the TWs but also helped them retain the TWs over time. In addition, a more interesting finding of the study was that the superiority of the IVT participants over the IVA participants with respect to the acquisition of the TWs faded away in the delayed posttest that was meant to be a measure of the retention of the TWs over time. As the results of the study indicated, though both experimental groups (IVA and IVT groups) outperformed the control group in the delayed posttest, there was no statistically significant difference between the 
experimental groups in the retention of the TWs over the five-week interval from the immediate posttest to the delayed posttest. This finding could be explained if we resort to Ausubel's (1968) meaningful learning theory. As it was pointed out above, the theory states that forgetting happens more quickly in rote learning because of the fact that materials are learned as disparate items in this type of learning, resulting in the learned items being forgotten more quickly. This prediction of the meaningful learning theory can explain why the performance of the participants in the IVT group diminished from the immediate posttest to the delayed posttest as these participants were taught on the TWs, as they were disparate learning materials. The participants in the IVA group, on the other hand, could retain nearly all their L2 vocabulary achievements over the five-week interval; in fact, their performance on the delayed posttest showed improvement over the immediate posttest that, of course, can be ascribed to unsystematic variables or to practice effects (Dunne, Pryor, \& Yates, 2005). Following Ausubel's (1968) meaningful learning theory, it can be proposed that the attachment of the acquired TWs to the previously-existing materials in the IVA participants' minds has helped them retain the TWs over time, a prediction already made by the meaningful learning theory.

\section{Conclusion}

In conclusion, the findings of the present study indicated that both instructed vocabulary teaching and incidental vocabulary acquisition are effective for developing intermediate EFL learners' L2 vocabulary knowledge. However, when the effects of these two approaches to developing L2 vocabulary knowledge were compared against each other in a short term, the findings showed that the former approach (instructed vocabulary teaching) is more effective than the latter one (incidental vocabulary acquisition) and the difference was statistically significant. However, when the participants in the two experimental groups were assessed on the TWs five weeks later after the immediate posttest, the statistically significant difference between the two approaches to L2 vocabulary instruction in the present study faded away as any remaining difference between the two approaches was found to be statistically insignificant.

The findings of this study have implications for L2 vocabulary research, pedagogy, and syllabus design. First, the fight over which approach to L2 vocabulary acquisition is more effective should be settled as, along with the findings of previous research (Horst, 2005; Horst, Cobb, \& Meara, 1998; Laufer, 2000; Schmitt, 2008), the present study indicated that both approaches are equally effective. Although instructed vocabulary teaching resulted in the acquisition of more TWs than incidental vocabulary acquisition in a short-term, the difference faded away in a long term. Therefore, as far as retention of the TWs were concerned, there is no difference between the two approaches. The implication for L2 vocabulary instruction is that teachers should not sacrifice one approach at the cost of the other in their classrooms since in that case they miss the opportunity to use the full potentialities of their instructional options. Further, teachers should be aware that the comparative positive effects of instructed vocabulary teaching and incidental vocabulary acquisition on the improvement of their learners' vocabulary knowledge should be evaluated in long terms. In fact, there are some evidence showing that incidental vocabulary acquisition is perhaps more effective that other L2 vocabulary teaching and learning options in long terms (see Huckin \& Coady, 1999; Wode, 1999).

At the end, there are some suggestions for further research. First, the time interval between the immediate posttest and the delayed posttest was only five weeks in the present study. Although a five-week interval is logically wide enough to enable us to make claims about long-term effects ( $\mathrm{Li}, 2010)$, it is suggested that future studies administer delayed posttests at an even wider interval to be able to make conclusions on the longer effects of instructed vocabulary teaching and incidental vocabulary acquisition on L2 vocabulary knowledge. Second, the present study made use of TWs belonging to different parts of speech (i.e., nouns, verbs, adjectives, and adverbs). However, because of the limited number of TWs for some of the parts of speech in the present study (e.g., there were only three verbs and one adverb among the TWs), it was not statistically possible to determine whether the effects of instructed vocabulary teaching and incidental vocabulary acquisition would differ according the part-of-speech classes the TWs belonged to. Even though there is some preliminary evidence that this may be actually the case (e.g., Hulstijn, 2003; Pigada \& Schmitt, 2006), more empirical studies are needed to confirm the proposition. The present research can be replicated with participants of different L2 proficiency levels, of different L2s, and of different ages to see whether the findings obtained can be generalized to other L2 learner populations.

\section{References}

Ausubel, D. (1968). Educational psychology: A cognitive view. New York: Rinehart \& Winston.

Bogaards, P., \& Laufer, B. (Eds.). (2004). Vocabulary in a second language: Selection, acquisition, and testing. Amsterdam: John Benjamins Publishing. Doi: http://dx.doi.org/10.1075/11lt.10.

Coady, J., \& Huckin, T. (1997). Second language vocabulary acquisition: A rationale for pedagogy. Cambridge: Cambridge University Press.

Dörnyei, Z. (2009). The psychology of second language acquisition. Oxford: Oxford University Press.

Dunne, M., Pryor, J., \& Yates, P. (2005). Becoming a researcher: A research companion for the social sciences. McGraw-Hill Education.

Eckerth, J., \& Tavakoli, P. (2012). The effects of word exposure frequency and elaboration of word processing on incidental L2 vocabulary acquisition through reading. Language Teaching Research, 16(2), 227-252. Doi: http://dx.doi.org/10.1177/1362168811431377. 
Elgort, I., \& Warren, P. (2014). L2 vocabulary learning from reading: Explicit and tacit lexical knowledge and the role of learner and item variables. Language Learning, 64(2), 365-414, doi: http://dx.doi.org/10.1111/lang.12052.

Gu, Y. (2013). Second language vocabulary. In J. Hattie, \& E. M. Anderson (Eds.), International guide to student achievement (pp. 307-309). New York: Routledge.

Horst, M. (2005). Learning L2 vocabulary through extensive reading: A measurement study. Canadian Modern Language Review, 61(3), 355-382, doi: http://dx.doi.org/10.3138/cmlr.61.3.355.

Horst, M., Cobb T., \& Meara, P. (1998). Beyond A Clockwork Orange: Acquiring second language vocabulary through reading. Reading in a Foreign Language, 11(2), 207-223.

Huckin, T., \& Coady, J. (1999). Incidental vocabulary acquisition in a second language. Studies in Second Language Acquisition, 21(2), 181-193, doi: http://dx.doi.org/10.1017/S0272263199002028.

Hulstijn, J. H. (2003). Incidental and intentional learning. In C. Doughty \& M. H. Long (Eds.), Handbook of second language acquisition (pp. 349-381). Oxford: Blackwell, doi: http://dx.doi.org/10.1002/9780470756492.ch12.

Joe, A. (1998). What effects do text-based tasks promoting generation have on incidental vocabulary acquisition? Applied Linguistics, 19(3), 357-377, doi: http://dx.doi.org/10.1093/applin/19.3.357.

Laufer, B. (2000). Task effect on instructed vocabulary learning: The hypothesis of 'involvement'. Selected Papers from AILA '99 Tokyo (pp. 47-62). Tokyo: Waseda University Press.

Laufer, B., \& Girsai, N. (2008). Form-focused instruction in second language vocabulary learning: A case for contrastive analysis and translation. Applied Linguistics, 29(4), 694-716, doi: http://dx.doi.org/10.1093/applin/amn018.

Laufer, B., \& Hulstijn, J. (2001). Incidental vocabulary acquisition in a second language: The construct of task-induced involvement. Applied Linguistics, 22(1), 1-26, doi: http://dx.doi.org/10.1093/applin/22.1.1.

Lewis, M. (1993). The Lexical Approach: The state of ELT and a way forward. Hove: Language Teaching Publications.

Lewis, M. (1997). Implementing the Lexical Approach: Putting theory into practice. Hove: Language Teaching Publications.

Li, S. (2010). The effectiveness of corrective feedback in SLA: A meta-analysis. Language Learning, 60(2), 309-365, doi: http://dx.doi.org/10.1111/j.1467-9922.2010.00561.x.

Meara, P. (2009). Connected words: Word associations and second language vocabulary acquisition. Amsterdam: John Benjamins Publishing, doi: http://dx.doi.org/10.1075/11lt.24.

Oliver, P. (2003). The student's guide to research ethics. Buckingham, UK: Open University Press.

Pallant, J. (2001). SPSS survival manual. Buckingham, UK: Open University Press.

Pigada, M., \& Schmitt, N. (2006). Vocabulary acquisition from extensive reading: A case study. Reading in a Foreign Language, 18(1), 1-28.

Reynolds, B. L. (2015). The effects of word form variation and frequency on second language incidental vocabulary acquisition through reading. Applied Linguistics Review, 6(4), 467-497, doi: http://dx.doi.org/10.1515/applirev-20150021.

Schmidt, R. W. (1990). The role of consciousness in second language learning. Applied Linguistics, 11(2), 129-158, doi: http://dx.doi.org/10.1093/applin/11.2.129

Schmidt, R. (1992). Awareness and second language acquisition. Annual review of Applied Linguistics, 13, 206-226, doi: http://dx.doi.org/10.1017/S0267190500002476.

Schmitt, N. (2008). Review article: Instructed second language vocabulary learning. Language Teaching Research, 12(3), 329-363, doi: http://dx.doi.org/10.1177/1362168808089921.

Takač, V. P. (2008). Vocabulary learning strategies and foreign language acquisition. New York: Multilingual matters.

Walters, J., \& Bozkurt, N. (2009). The effect of keeping vocabulary notebooks on vocabulary acquisition. Language Teaching Research, 13(4), 403-423, doi: http://dx.doi.org/10.1177/1362168809341509.

Webb, S. (2005). Receptive and productive vocabulary learning: The effects of reading and writing on word knowledge. Studies in Second Language Acquisition, 27, 33-52, doi: http://dx.doi.org/10.1017/s0272263105050023.

Webb, S. (2008). The effects of context on incidental vocabulary learning. Reading in a Foreign Language, 20(2), 232-245.

Wode, H. (1999). Incidental vocabulary acquisition in the foreign language classroom. Studies in Second Language Acquisition, 21(2), 243-258, doi: http://dx.doi.org/10.1017/S0272263199002053. 